\title{
Piscine orthoreovirus subtype 3 (PRV-3) causes heart inflammation in rainbow trout (Oncorhynchus mykiss)
}

\author{
Niccoló Vendramin ${ }^{1 *+}$ (D, Dhamotharan Kannimuthu ${ }^{2 \dagger}$, Anne Berit Olsen ${ }^{3}$, Argelia Cuenca ${ }^{1}$, \\ Lena Hammerlund Teige ${ }^{2}$, Øystein Wessel ${ }^{2}$, Tine Moesgaard Iburg ${ }^{1}$, Maria Krudtaa Dahle ${ }^{4}$, Espen Rimstad ${ }^{2}$ \\ and Niels Jørgen Olesen'
}

\begin{abstract}
Piscine orthoreovirus (PRV) mediated diseases have emerged throughout salmonid aquaculture. Three PRV subtypes are currently reported as causative agents of or in association with diseases in different salmonid species. PRV-1 causes heart and skeletal muscle inflammation (HSMI) in Atlantic salmon (Salmo salar) and is associated with jaundice syndrome in farmed chinook salmon (Oncorhynchus tshawytscha). PRV-2 causes erythrocytic inclusion body syndrome (EIBS) in coho salmon in Japan. PRV-3 has recently been associated with a disease in rainbow trout (Oncorhynchus mykiss) characterized by anaemia, heart and red muscle pathology; to jaundice syndrome in coho salmon (Oncorhynchus kisutch). In this study, we conducted a 10-week long experimental infection trial in rainbow trout with purified PRV-3 particles to assess the causal relationship between the virus and development of heart inflammation. The monitoring the PRV-3 load in heart and spleen by RT-qPCR shows a progressive increase of viral RNA to a peak, followed by clearance without a measurable change in haematocrit. The development of characteristic cardiac histopathological findings occurred in the late phase of the trial and was associated with increased expression of CD8+, indicating cytotoxic T cell proliferation. The findings indicate that, under these experimental conditions, PRV-3 infection in rainbow trout act similarly to PRV-1 infection in Atlantic salmon with regards to immunological responses and development of heart pathology, but not in the ability to establish a persistent infection.
\end{abstract}

\section{Introduction}

Piscine orthoreovirus (PRV) causes or are associated with emerging diseases in salmonid aquaculture. PRV belongs to the family Reoviridae, sub-family Spinareovirinae, genus Orthoreovirus. It has a double stranded RNA genome consisting of 10 segments [1]. The virion has a double protein capsid with icosahedral symmetry and no envelope [1]. PRV resists cultivation in cell culture monolayers, however, ex vivo infection of naïve red blood cells has been demonstrated [2]. Efficient propagation of

\footnotetext{
*Correspondence: niven@aqua.dtu.dk

${ }^{\dagger}$ Niccoló Vendramin and Dhamotharan Kannimuthu contributors equally to this work

${ }^{1}$ National Institute of Aquatic Resources, Technical University of Denmark, Kongens Lyngby, Denmark

Full list of author information is available at the end of the article
}

the virus relies on in vivo experimental challenge in susceptible fish.

Three subtypes of PRV have been reported and are denoted as PRV-1, PRV-2, and PRV-3. Subtypes 1 and 2 have recently been identified as aetiological agents of disease in salmonids through infection with purified virus. PRV-1 causes heart and skeletal muscle inflammation (HSMI) in Atlantic salmon (Salmo salar) [3]. The disease was first diagnosed in 1999 in Norway [4, 5]; HSMI has also been reported in Scotland and Canada [6]. In Norway, the causative relationship between PRV-1 and HSMI was demonstrated [3]. As the disease name implies, the major histopathological findings are in located in the heart and red skeletal muscle. Affected fish show pancarditis with epicarditis, mononuclear cell infiltrations in the atrium and spongy and compact layers of the cardiac 
ventricle and necrotic cardiomyocytes. Severely affected fish also have red muscle inflammation [7].

PRV-2 was shown to cause erythrocytic inclusion body syndrome (EIBS) in coho salmon (Oncorhynchus kisutch) in 2016 [8] in Japan. The anaemic condition denoted as EIBS was first described in 1977 in rainbow trout [9] and in 1987 in chinook salmon from the Pacific Northwest of North America [10], however, as these occurrences predate the discovery of PRV-2, it remains unknown as to whether these historical EIBS cases are equivalent to the PRV-2 causing EIBS as diagnosed in Japan. To date, PRV-2 has not been reported outside of Japan.

PRV-3 was detected in 2013 following a thorough investigation of unexplained mortalities in young rainbow trout (Oncorhynchus mykiss) farmed in fresh water in Norway [11]. After detection of the virus, infection trials were conducted to assess its pathogenicity and the risk associated with its introduction to salmonid aquaculture in Europe. Those experimental trials showed that PRV-3 replicated in rainbow trout blood and efficiently transmitted to naïve host in a cohabitation trial, while its capacity of replicating in Atlantic salmon is limited [12]. The PRV-3 genome was sequenced and compared with PRV-1 showing that PRV-3 is more closely related to PRV-1 than PRV-2 [13].

PRV-3 antigenic properties were analyzed with antibodies raised against homologous proteins of PRV-1. Western blot analysis of PRV-3 infected blood cells have demonstrated that polyclonal rabbit antisera raised against the homologous proteins of PRV-1 cross-reacted with the PRV-3 proteins $\sigma 1, \sigma 3, \sigma N S, \mu 1, \mu N S$, and $\lambda 1$ [13].

The orthoreoviruses are, in general, ubiquitous in their respective niches. The mere detection of the virus is therefore not necessarily indicative of disease causality. For example, PRV-1 is present in almost every cohort of farmed Atlantic salmon in the marine phase [3] and PRV-3 was detected in non-diseased adult rainbow trout in Norway [14]. Recently the virus was detected in several European countries, including Scotland, Germany, Italy and Denmark both from disease outbreaks and asymptomatic fish [13], the virus might also be associated with proliferative darkening syndrome (PDS) in brown trout [15]; finally PRV-3 was detected in clinically affected coho salmon in Chile $[16,17]$. The main aim of our study was to demonstrate eventual causality between PRV-3 infection in rainbow trout and development of cardiac lesions as observed in field cases and previous challenge experiments. Injection with blood from infected fish was used previously in infection trials, but did not prove that PRV-3 was in fact the sole causative agent of the disease, since other pathogens/viruses could be present in the sample.
In this study, we set out to demonstrate an eventual causality between a disease recently described in rainbow trout [11], and the associated Piscine orthoreovirus (PRV) [13]. To achieve this goal, PRV-3 was purified from experimentally infected rainbow trout blood and used in the challenge model previously developed to compare the infection progress and disease development with a control group injected with PRV-3 infected blood.

The viral RNA kinetics in the heart and spleen and PRV protein expression in erythrocytes were assessed, along with the development of heart pathology. In addition, the immune response was monitored through gene expression analysis and detection of PRV specific antibodies.

\section{Materials and methods}

\section{Virus purification}

The challenge material, consisting of purified PRV-3 particles or PRV-3 infected blood, originated from intra peritoneal (i.p.) injected fish from a PRV-3 challenge trial described earlier [13]. PRV-3 particles (isolate NOR/060214) were purified from the PRV-3 infected blood $(500 \mu \mathrm{L}, \mathrm{Ct} 19.7)$ exactly as stated in [13]. Fractions of $0.5 \mathrm{~mL}$ were collected using a syringe with a $23 \mathrm{G}$ needle. The density of the fractions was determined by cross referencing to the refractive index [18]. The quantity of PRV-3 in the fractions was determined using RT-qPCR. Fractions with a density corresponding to that of PRV were chosen for dialysis. The purity of the samples was inspected by transmission electron microscopy (TEM) and analyzed by Next Generation Sequencing (NGS) as described by Dhamotaran et al. [13].

\section{Experimental challenge}

Rainbow trout were obtained from eyed eggs provided by a Danish commercial fish farm officially registered free of IPNV, IHNV, VHSV and bacterial kidney disease (BKD). After iodophor disinfection, the eggs were hatched and fish were grown in the wet laboratory facilities of the European Union Reference Laboratory for fish disease (EURL, Copenhagen, Denmark) using recirculated tap water disinfected by UV light. Before infection, the specific pathogen free (SPF) rainbow trout were moved into the high containment infection facility with fresh water at a constant temperature of $12{ }^{\circ} \mathrm{C} \pm 1{ }^{\circ} \mathrm{C}$. Each tank was supplied with flow-through UV disinfected water (1 full water exchange per day), furthermore one recirculating unit (EHEIM Professional 4+) was added to each tank to increase water quality and reduce water usage.

A total of 500 SPF rainbow trout of $10 \mathrm{~g}$ in average were kept in tanks with $5 \mathrm{~L} / \mathrm{h}$ flow-through fresh water renewal using the following conditions: $12{ }^{\circ} \mathrm{C} \pm 1{ }^{\circ} \mathrm{C}$, L:D 12:12, stocking density below $60 \mathrm{~kg} / \mathrm{m}^{3}$, and feeding of $1.5 \%$ of biomass/day. The fish were divided into three 
groups: Negative control; purified PRV-3 particles and positive control PRV-3 infected blood.

In order to have comparable biomass in the different groups, the negative control group of 500 Lts capacity accommodated 300 rainbow trout, the two experimental tanks accommodating fish challenged with purified PRV-3 particles and positive controls were 180 Lts accommodating 100 rainbow trout each. In all tanks the ratio between injected (shedders) and cohabitants was 50:50. To set up the cohabitation trial, shedder fish were anaesthetized by immersion in water containing benzocaine $(80 \mathrm{mg} / \mathrm{L}$ water), and then i.p. injected with $0.1 \mathrm{ml}$ of challenge or mock inoculum. The PRV-3 RNA load in the infected blood inoculum was Ct 26.3 per $5 \mu \mathrm{L}$; whereas in the purified viral particle inoculum the PRV-3 load was assessed as Ct 32.7 per $5 \mu \mathrm{L}$. Mock infection with blood from naïve fish (tested negative for PRV3) diluted in L-15 medium was performed in the same manner on $50 \%$ of the negative control fish. Injected fish were marked by adipose fin clipping. Sampling took place at 2, 4, 6, 8, 10 weeks post-challenge (wpc) and included six shedders and six cohabitants in the exposed tanks, whereas 2 mock injected fish and 2 negative control cohabitants where sampled. Sampling specifics are provided in Table 1.

\section{Sampling}

Upon sampling, fish were euthanized with benzocaine $(800 \mathrm{mg} / \mathrm{L})$. Blood was collected from the caudal vein in heparinized tubes (Kruuse ltd UK). Heparinized blood was centrifuged ( $130 \mathrm{~g}$ for $10 \mathrm{~min}$ ) and plasma and blood cells were separated. Blood was used for Western blot (WB) and plasma for assessing specific antibody. An aliquot of heparinized blood was centrifuged $(12000 \mathrm{~g}$ for $5 \mathrm{~min}$ ) in glass microhematocrit tubes (Vitrex Medical A/S) with specific centrifuge (Nüve) and haematocrit (hct) assessed visually with specific scale.

Table 1 Design of the experimental trial

\begin{tabular}{|c|c|c|c|c|c|c|}
\hline Group & Number of fish & $\begin{array}{l}\text { Trial } \\
\text { length } \\
\text { (weeks) }\end{array}$ & $\begin{array}{l}\text { Sampling time points } \\
\text { (weeks post-challenge- } \\
\text { wpc) }\end{array}$ & $\begin{array}{l}\text { Fish sampled } \\
\text { per time point }\end{array}$ & Samples & Analysis \\
\hline \multirow[t]{8}{*}{ Negative control } & \multirow[t]{4}{*}{150 mock injected } & \multirow[t]{4}{*}{10} & \multirow[t]{4}{*}{$2,4,6,8,10$} & \multirow[t]{4}{*}{2} & Blood & Antibody detection \\
\hline & & & & & Heart & Virus qPCR; CD4 CD8 \\
\hline & & & & & Spleen & Virus qPCR; IFN \\
\hline & & & & & Organs & Histopathology \\
\hline & \multirow[t]{4}{*}{150 cohabitants } & \multirow[t]{4}{*}{10} & \multirow[t]{4}{*}{$2,4,6,8,10$} & \multirow[t]{4}{*}{2} & Blood & $\begin{array}{l}\text { WB-antibody } \\
\text { detection-Hct }\end{array}$ \\
\hline & & & & & Heart & Virus qPCR; CD4 CD8 \\
\hline & & & & & Spleen & Virus qPCR; IFN \\
\hline & & & & & Organs & Histopathology \\
\hline \multirow[t]{8}{*}{ Purified PRV-3 particles } & \multirow[t]{4}{*}{50 purified PRV-3 injected } & \multirow[t]{4}{*}{10} & \multirow[t]{4}{*}{$2,4,6,8,10$} & \multirow[t]{4}{*}{6} & Blood & Antibody detection \\
\hline & & & & & Heart & Virus qPCR; CD4 CD8 \\
\hline & & & & & Spleen & Virus qPCR \\
\hline & & & & & Organs & Histopathology \\
\hline & \multirow[t]{4}{*}{50 cohabitants } & \multirow[t]{4}{*}{10} & \multirow[t]{4}{*}{$2,4,6,8,10$} & \multirow[t]{4}{*}{6} & Blood & $\begin{array}{l}\text { WB-antibody } \\
\text { detection-Hct }\end{array}$ \\
\hline & & & & & Heart & Virus qPCR; CD4 CD8 \\
\hline & & & & & Spleen & Virus qPCR; IFN \\
\hline & & & & & Organs & Histopathology \\
\hline \multirow[t]{8}{*}{ Positive control } & \multirow{4}{*}{$\begin{array}{l}50 \text { PRV-3 infected blood } \\
\text { injected }\end{array}$} & \multirow[t]{4}{*}{10} & \multirow[t]{4}{*}{$2,4,6,8,10$} & \multirow[t]{4}{*}{6} & Blood & Antibody detection \\
\hline & & & & & Heart & Virus qPCR; CD4 CD8 \\
\hline & & & & & Spleen & Virus qPCR \\
\hline & & & & & Organs & Histopathology \\
\hline & \multirow[t]{4}{*}{50 cohabitants } & \multirow[t]{4}{*}{10} & \multirow[t]{4}{*}{$2,4,6,8,10$} & \multirow[t]{4}{*}{6} & Blood & $\begin{array}{l}\text { WB-antibody } \\
\text { detection-Hct }\end{array}$ \\
\hline & & & & & Heart & Virus qPCR; CD4 CD8 \\
\hline & & & & & Spleen & Virus qPCR; IFN \\
\hline & & & & & Organs & Histopathology \\
\hline
\end{tabular}

a In addition 9 fish were collected prior to exposure and investigated for presence of PRV-3 and heart histopathology. 
The heart was cut in two equal halves along the midsagittal axis; one half was stored in 10\% neutral-buffered formalin for histopathological evaluation, and the other half was divided into two aliquots: one was stored in RNALater $^{\circledR}$ (ThermoFisher Scientific Inc, USA) for gene expression analysis (CD4 and CD8) and one was stored in RLT buffer (c QIAGEN) for quantifying viral RNA. The spleen was divided into three aliquots: one was stored in $10 \%$ neutral-buffered formalin, one was stored in RNALater $^{\circledR}$ (ThermoFisher Scientific Inc,) for gene expression analysis and one was stored in RLT buffer (QIAGEN) for quantifying viral RNA. Gill, liver, pancreas and pyloric caeca, distal intestine, red and white muscle, mid kidney were also collected and stored in $10 \%$ neutral-buffered formalin for histopathological evaluation.

\section{Quantification of PRV-3 in the heart and spleen}

RT-qPCR was performed on RNA purified from fish tissue. After processing the sample with Tissue Lyzer (QIAGEN, Hilden, Germany), total RNA was isolated using QIAcube and the RNeasy Mini Kit (QIAGEN) according to the manufacturer's recommendations.

RT-qPCR was performed with $5 \mu \mathrm{L}$ of template using the QuantiTect Probe RT-PCR Kit (QIAGEN), primers and probes, and conditions as described elsewhere [11], with ROX as a reference dye.

All RT-qPCR analyses were performed using Agilent Mx3005P and Mx3000P qPCR-system (Agilent Technologies, Santa Clara, United States), and MxPro (v. 4.10) software, using the adaptive Baseline function. Cycle thresholds $(\mathrm{Ct})$ were set manually to the same value in all the runs $(\mathrm{dR}=380)$, in order to be able to compare $\mathrm{Ct}$ values among runs. Fish were considered virus positive at Ct levels below 35 and suspect between Ct 35-40; Ct values above 40 were negative.

\section{Western blotting}

Purified PRV-3 virus particles or blood pellets pooled from three cohabitant fish were mixed with XT buffer and $\mathrm{XT}$ reducing agent (Bio-rad), heated for $5 \mathrm{~min}$ at $95{ }^{\circ} \mathrm{C}$ and loaded onto a $4-12 \%$ criterion XT bis-tris gel. Separated proteins were transferred onto a $0.2 \mu \mathrm{m}$ PVDF membrane using Trans Blot Turbo Transfer system (Biorad) and incubated overnight at $4{ }^{\circ} \mathrm{C}$ with antiserum against PRV-1 proteins; anti- $\sigma 1$ (1:1000) [19], anti- $\sigma 3$ $(1: 500)[1]$, anti- $\mu 1 \mathrm{C}(1: 500)$ [19] and anti-actin (1:500) (Sigma). After washing $4 \times 15 \mathrm{~min}$ the membranes were incubated with the secondary antibody horse radish peroxidase (HRP)-conjugated anti-rabbit IgG (Amersham, GE Healthcare, Buchinghamshire, UK) (1:20 000). The membranes were washed $4 \times 15$ min and stained with the Clarity Western ECL Substrate kit (Bio-rad). MagicMark was used as molecular weight ladder (XP Western
Protein Standard, Invitrogen). Images were acquired using ChemiDoc XRS+ system and Image one software (Bio-rad).

\section{PRV immunoassay}

The specific antibody response to PRV infection was measured as mean fluorescence intensity (MFI) in plasma samples of challenged rainbow trout using a bead based immunoassay as described earlier [20]. Briefly, plasma samples from cohabitant fish sampled from the the negative control, positive control and experimental groups were analysed for antibodies against $\mu 1 \mathrm{C}$. Beads, conjugated with and PRV-1 $\mu 1 \mathrm{C}$ recombinant protein, were incubated with plasma harvested at $0,4,6,8$ and $10 \mathrm{wpc}$ from cohabitants (n 6 per time point). The $\mu 1 \mathrm{C}$ protein has $91.5 \%$ homology at the aminoacid level between PRV-1 and PRV-3 [13].

\section{Histopathology}

Hearts from 60 fish exposed to purified PRV particles and 60 fish from the positive control group were sampled at regular intervals and examined by histopathology; in addition, 20 hearts from the negative control group were assessed. Prior to exposure 9 fish were sampled and analysed as well (Table 1).

Tissue samples collected in $10 \%$ neutral-buffered formalin were embedded in paraffin and processed into sections of 3-4 $\mu \mathrm{m}$, stained with haematoxylin and eosin (H\&E) and examined by light microscopy. Pathological findings in the heart were classified as (1) mild (one to a few lesions), (2) moderate (more extended distribution of lesions) and (3) severe (most of the heart sample affected) [21].

\section{Immune gene expression}

In brief, tissues were homogenized in $650 \mu \mathrm{L}$ QIAzol lysis reagent with $5 \mathrm{~mm}$ steel beads in a Tissue Lyser II for $5 \mathrm{~min}$. Following chloroform extraction, $350 \mu \mathrm{L}$ of aqueous phase was loaded into an automated QIAcube (Qiagen) for RNA purification. Total RNA concentration was measured using a NanoDrop ND-1000 spectrophotometer (Thermo Fisher Scientific). For gene expression analysis, cDNA was synthesized using 500 ng of total RNA using the QuantiTect Reverse Transcription kit (Qiagen) which includes a gDNA wipeout step. The qPCR was performed in duplicates with $10 \mathrm{ng}$ of cDNA input in total volume of $10 \mu \mathrm{L}$ per reaction using Maxima SYBR Green/ROX qPCR Master Mix (Fisher Scientific) and $500 \mathrm{nM}$ forward and reverse primers (Table 2). The assay included $95{ }^{\circ} \mathrm{C}$ for $10 \mathrm{~min}, 40$ cycles of $94{ }^{\circ} \mathrm{C}$ for $15 \mathrm{~s}$ and $60{ }^{\circ} \mathrm{C}$ for $30 \mathrm{~s}$. The melting curve analysis confirmed the specificity of each SYBR qPCR assay, and elongation factor $(\mathrm{EF} 1 \alpha)$ mRNA was used for normalization by 
Table 2 Primers used for immune gene analysis

\begin{tabular}{|c|c|c|c|c|}
\hline Gene & Primer sequences & Amplicon length & Reference & Gene Bank No. \\
\hline Elongation Factor (EF1a) & $\begin{array}{l}\text { GATCCAGAAGGAGGTCACCA } \\
\text { TTACGTTCGACCTTCCATCC }\end{array}$ & 150 & [43] & AF498320.1 \\
\hline$M x$ & $\begin{array}{l}\text { AGCTCAAACGCCTGATGAAG } \\
\text { ACCCCACTGAAACACACCTG }\end{array}$ & 142 & [43] & NM_001171901 \\
\hline Viperin & $\begin{array}{l}\text { ACGACCTCCAGCTCCCAAGT } \\
\text { GTCCAGGTGGCTCTTCCTGC }\end{array}$ & 173 & [43] & AF076620.1 \\
\hline Interferon type 1 & $\begin{array}{l}\text { AAAACTGTTTGATGGGAATATGAAA } \\
\text { TGTTTCAGTCTCCTCTCAGGTT }\end{array}$ & 141 & [43] & NM_001124531 \\
\hline Interferon gamma & $\begin{array}{l}\text { CAAACTGAAAGTCCACTATAAGATCTCCA } \\
\text { GGTCCAGCCTCTCCCTCAC }\end{array}$ & 188 & [44] & FM864345.1 \\
\hline CD-4 & $\begin{array}{l}\text { CCTGCTCATCCACAGCCTAT } \\
\text { CTTCTCCTGGCTGTCTGACC }\end{array}$ & 111 & [43] & AY973030.1 \\
\hline CD-8 alpha & $\begin{array}{l}\text { AGTCGTGCAAAGTGGGAAAG } \\
\text { GGTTGCAATGGCATACAGTG }\end{array}$ & 123 & [43] & NM_001124263 \\
\hline
\end{tabular}

the $\Delta \Delta \mathrm{Ct}$ method. In Figures $3 \mathrm{C}, \mathrm{D}$ and 5 all the PRV-3 infected groups were compared to time-matched samples from negative control groups. At each time point, gene expression of fish exposed to purified PRV-3 particles and PRV-3 infected blood respectively were compared to the negative control at that specific time point. The fold changes in gene expression in the negative control group sampled at weeks $2,4,6,8$ and 10 were compared to the same group at week 0 .

\section{Statistical analysis}

To assess the significant differences in immune gene expression between the control group and PRV-3 infected groups, the statistical analysis was performed using one way ANOVA with Dunnets multiple comparison test [22]. The correlation between viral load and immune transcripts were done by non-parametric Spearman correlation test [23].

\section{Results}

Characterization of purified PRV-3

Purified PRV-3 particles were observed in TEM as spherical, non-enveloped virions of approximately $75 \mathrm{~nm}$ in diameter resembling PRV-1 particles [3] (Figure 1A). No other type of virus particles were found. In western blotting of purified virus, antibodies against PRV-1 $\sigma 1, \sigma 3$
A

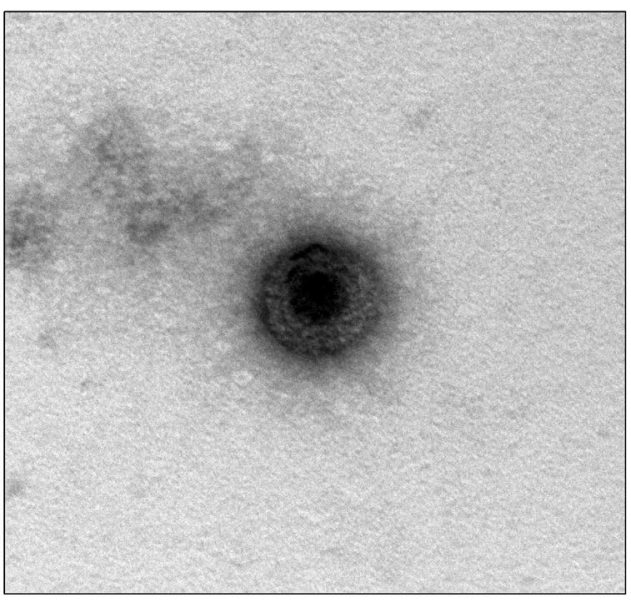

B

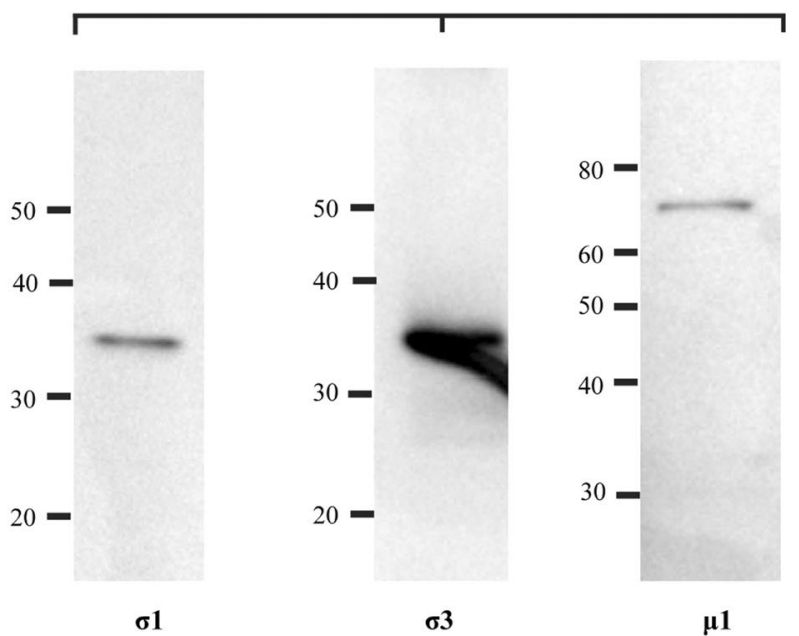

Figure 1 Purified PRV-3 particles. A Transmission electron microscopy (TEM) of purified PRV-3 viral particles. B Western blot analysis of proteins from purified PRV-3 particles using antiserum raised against PRV-1 $\sigma 1, \sigma 3$ and $\mu 1$ proteins. Observed bands correspond to predicted full length proteins of $35 \mathrm{kDa}, 37 \mathrm{kDA}$ and $74 \mathrm{kDa}$, respectively. 
and $\mu 1$ recognized the corresponding proteins of PRV-3, observed as bands of 35, 37 and $74 \mathrm{kDa}$ (Figure 1B).

\section{PRV-3 RNA viral kinetics in heart and spleen}

The PRV-3 RNA load in heart and spleen showed a similar trend for the positive control group, inoculated with PRV-3 infected blood, as for the group inoculated with purified PRV-3 particles. An acute phase characterized by a peak PRV-3 load was followed by virus clearance (Figures $2 \mathrm{~A}$ and $\mathrm{B}$ ).

In the positive control group (injected with PRV-3 infected blood) viral RNA peaked at 2 wpc (median $\mathrm{Ct}$ 26.8 in the heart and 22.5 in the spleen) while the peak occurred at $6 \mathrm{wpc}$ in the cohabitants (median Ct 21 in the heart and 18.1 in the spleen). In fish challenged with purified PRV-3, viral RNA peaked at $4 \mathrm{wpc}$ in the injected group (median Ct 28.9 in the heart and 24.8 in the spleen) and at $6 \mathrm{wpc}$ in the cohabitants (median Ct 25 in the heart and 22.7 in the spleen).

After the peak phase of infection, the number of PRV positive fish per sampling point decreased and the Ct values of the positive fish increased, indicating viral clearance. At the end of the trial (10 wpc) PRV-3 RNA could not be detected in the spleen or heart from shedders of the positive control group and only in three spleen and four heart samples from the six cohabitants. In viruspositive samples, the $\mathrm{Ct}$ values were close to the set detection limit (Ct 35). A similar observation was made at 10 wpc in fish infected with purified PRV-3. No PRV-3 RNA was detected in spleen samples from shedders, whereas the five positive out of six spleen samples from the cohabitants had high $\mathrm{Ct}$ values $(>29)$. Only one out of six heart samples from the shedders and five out of six from the cohabitants tested positive (Ct values $>30$ ) at 10 wpc. No PRV-3 was detected in samples from the negative control group.

No significant differences in haematocrit were observed between the groups (data not shown).

\section{Histopathology}

Histopathological findings in hearts consisting in the PRV-3 associated pathology described earlier [11, 12], were detected after peak load of PRV-3 in hearts in the respective groups. In the group challenged with purified PRV-3 particles, 2 shedders and 2 cohabitant fish had heart lesions, whereas 1 shedder and 7 cohabitants show
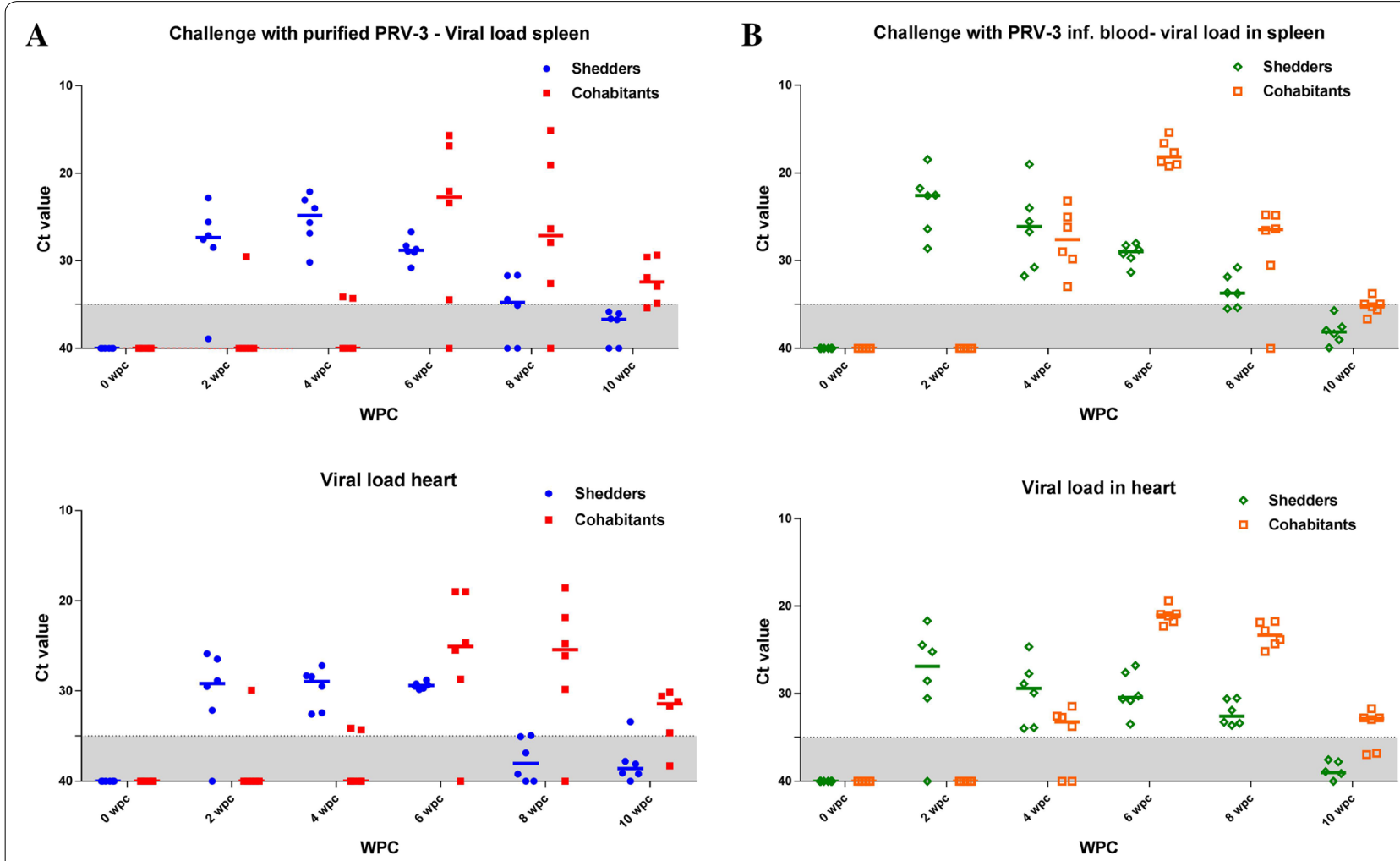

Figure 2 PRV-3 infection kinetics. RT-qPCR of PRV-3 segment S1 in spleen and heart. Colored dots indicate Ct values of individual fish while horizontal bars show the median Ct value. Samples were considered virus positive at Ct levels below 35 and suspected between Ct 35-40 (grey shaded area); Ct values above 40 are negative. A Shedders (Blue) and cohabitants (red) in tank challenged with purified PRV-3 particles. B Shedders (green) and cohabitants (orange) in tank challenged with PRV-3 infected blood. 
heart pathology in the positive control group. Prevalence and distribution of heart lesions at each time point are shown in Table 3. The lesions observed were mild in fish infected with purified PRV-3 particles and mild to moderate in positive controls. Typical findings were epicarditis and focal to multifocal endo- and myocarditis in atrium and stratum spongiosum of the ventricle and perivasculitis and myocarditis in stratum compactum of the ventricle (Figures $3 \mathrm{~A}$ and B). Histopathological findings consisting of epicarditis and a focal inflammatory reaction involving the interface layer between stratum compactum and stratum spongiosum were occasionally observed in all groups throughout the experiment (Additional file 1). Since they were clearly distinguishable from PRV-3 associated pathology, they were prudentially removed while assessing the development of PRV-3 pathology.

\section{PRV-3 protein detection}

Western blot analysis of blood cells from cohabitants of fish injected with PRV-3 purified particles or infected blood, detected $\sigma 1$ viral proteins at $6 \mathrm{wpc}$, correlating with the peak phase of infection. No viral proteins were detected in blood cells after 6 wpc (Figure 4A).

\section{Development of specific antibodies against PRV}

There was a significant increase in $\mu 1 \mathrm{C}$-specific IgM in plasma from PRV-3 infected cohabitant fish compared to plasma of uninfected fish at $8 \mathrm{wpc}$, and the production continued to increase at $10 \mathrm{wpc}$. Notably, large variations between individuals were observed (Figure 4B).

At $6 \mathrm{wpc}$ the group challenged with PRV-3 infected blood had higher specific antibody levels than the purified PRV-3 particle group, but this was opposite at 10 wpc.

\section{Immune gene expression}

The innate antiviral immune response following PRV-3 infection was targeted by measuring $\mathrm{Mx}$, Viperin, interferon type 1 and interferon $\gamma$ gene expression patterns in spleen. The $\mathrm{T}$ cell response in the heart was analyzed by targeting the T-cell markers CD4 and CD8. The Mx and Viperin gene expressions were significantly upregulated in the groups challenged with PRV-3 infected blood and purified virus particles, and correlated well with the viral load (Spearman $r=0.76$ ) (Figure 5). In the shedders, the antiviral gene expression increased significantly along with the viral load at $2 \mathrm{wpc}$ and $4 \mathrm{wpc}$, and subsided after 4 wpc. In the cohabitants, the antiviral gene expression shows an acute peak at $6 \mathrm{wpc}$ corresponding with the peak viral load. Both viral load and antiviral gene expression decreased after 6 wpc. In both cohabitant groups, CD4 and CD8 expression in heart remained equivalent to the 0 wpc control level until 8 wpc. The CD8 gene expression shows a particularly high increase (100-fold) peaking at $10 \mathrm{wpc}$ (Figures $3 \mathrm{C}$ and D). The CD4 expression was also significantly higher at $10 \mathrm{wpc}$. The $\mathrm{T}$ cell marker gene expression did not correlate with the viral peak, but with the inflammation scores in the heart.

\section{Discussion}

The major aim of this study was to investigate an eventual association between PRV-3 infection in rainbow trout and the development of heart pathology consistent with cardiac lesions observed in natural disease outbreaks associated with PRV-3 infection. The detection of PRV-3 RNA in apparently healthy fish has raised

Table 3 Prevalence and scores of histopathological findings in the hearts of PRV-3 challenged fish

\begin{tabular}{|c|c|c|c|c|c|c|c|c|c|c|c|c|}
\hline \multirow[t]{2}{*}{ WPC } & \multicolumn{6}{|c|}{ PRV-3 purified particles } & \multicolumn{6}{|c|}{ PRV-3 infected blood } \\
\hline & Shedder & Score & $\mathrm{Ct}$ & Cohab. & Score & $\mathrm{Ct}$ & Shedder & Score & $\mathrm{Ct}$ & Cohab. & Score & $\mathrm{Ct}$ \\
\hline 2 & $0 / 6$ & & & $0 / 6$ & & & $0 / 6$ & & & $0 / 6$ & & \\
\hline 4 & $0 / 6$ & & & $0 / 6$ & & & $0 / 6$ & & & $0 / 6$ & & \\
\hline 6 & $1 / 6$ & 1 & 29.5 & $0 / 6$ & & & $0 / 6$ & & & $0 / 6$ & & \\
\hline \multirow[t]{2}{*}{8} & $0 / 6$ & & & $0 / 6$ & & & $0 / 6$ & & & $2 / 6$ & 1.5 & 21.8 \\
\hline & & & & & & & & & & & 1.5 & 22.8 \\
\hline \multirow[t]{5}{*}{10} & $1 / 6$ & 1 & $>35$ & $2 / 6$ & 1 & 31.2 & $1 / 6$ & 1 & $>35$ & $5 / 6$ & 1 & 32.7 \\
\hline & & & & & 1 & 30.1 & & & & & 1 & 32.7 \\
\hline & & & & & & & & & & & 1 & $>35$ \\
\hline & & & & & & & & & & & 1 & 31.7 \\
\hline & & & & & & & & & & & 1 & 36.8 \\
\hline Positive hearts & 2 & & & 2 & & & 1 & & & 7 & & \\
\hline
\end{tabular}



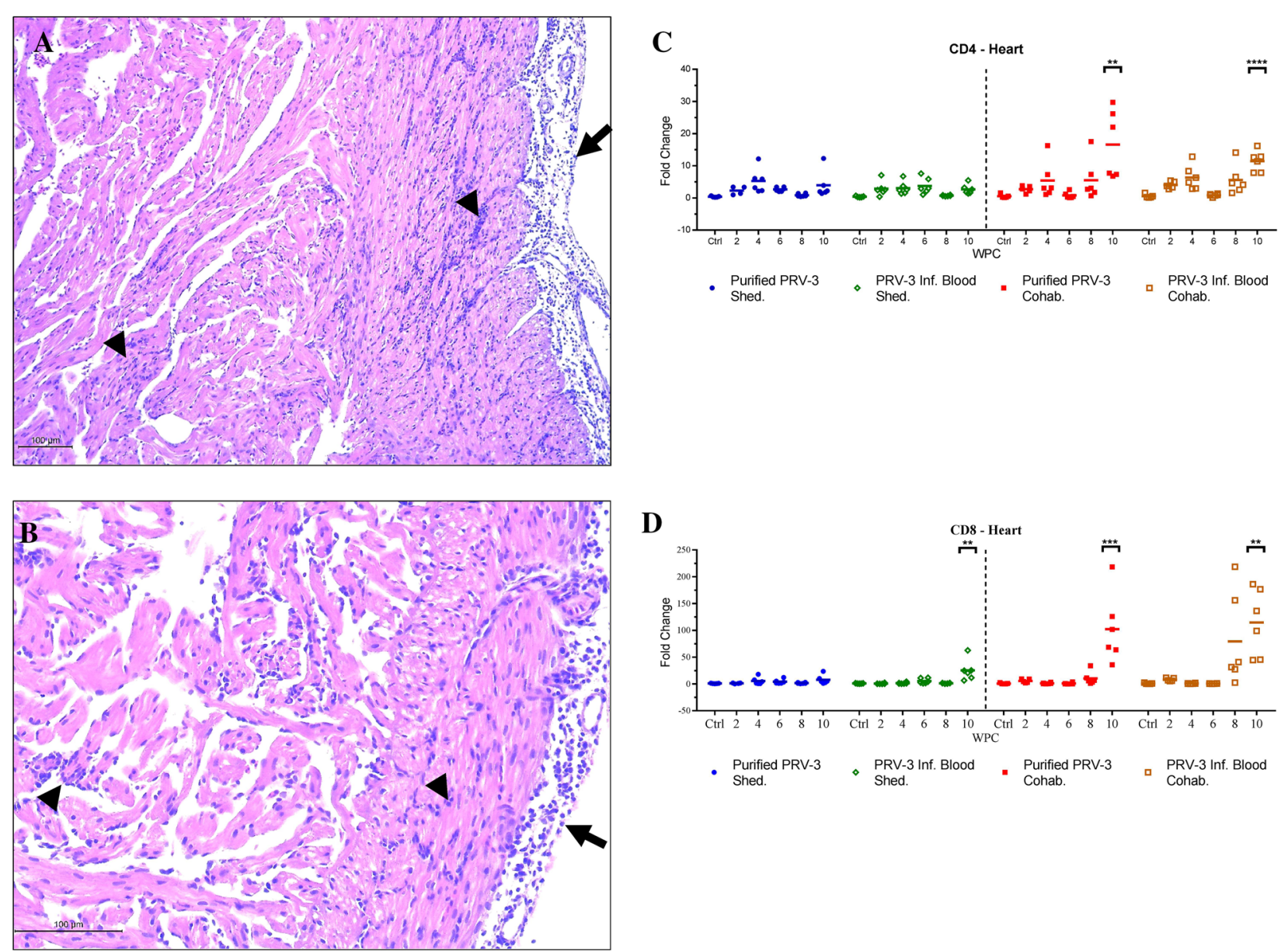

Figure 3 Histopathological findings and T-cell markers in the hearts of PRV-3 infected fish. A, B Rainbow trout infected with PRV-3 purified particles Epicarditis (long arrows) and inflammation in stratum compactum (outer layer) and stratum spongiosum (internal layer) of heart ventricle (arrow heads) (H\&E). C Relative expression of the T-cell marker CD4 in the heart. The Ct values were normalized against control fish from 0 wpc. Significant differences compared to control are shown in asterisks ${ }^{*} P<0.05{ }^{* *} P<0.001$ and ${ }^{* * *} P<0.0001$. D Relative expression of the T-cell marker $\mathrm{CD} 8$ in the heart. The $\mathrm{Ct}$ values were normalized against control fish from $0 \mathrm{wpc}$. Significant differences compared to control are shown in asterisks ${ }^{*} P<0.05{ }^{* *} P<0.001$ and ${ }^{* * *} P<0.0001$

questions in relation to the causative relationship between the virus and the disease. Koch's postulates have historically defined the criteria to demonstrate a causative relationship between infecting agents and disease [24]. Fulfillment of Koch's postulate relies on four main criteria, which are the presence of the disease agent in all disease cases; the possibility to isolate the agent in pure culture, the development of disease after the agent is inoculated in susceptible hosts and the re-isolation of the agent from the experimentally infected host. These criteria cannot be fulfilled for all disease-causing agents who resist culturing. According to the Rivers postulate, the viral agent should be isolated from a diseased individual and should induce the same disease when challenged with the purified viral inoculum as cell free extract and produce antibodies in a disease free individual of the same species [25]. The development of sequence based detection methods have led to further revision [26]. In recent years Atlantic salmon farming has in particular been challenged with a number of pathogens that resist cultivation [27] such as PRV-1 [3], piscine myocarditis virus (PMCV) $[28,29]$, and salmon gill poxvirus (SGPV) $[30,31]$. The diagnostic investigations that followed the appearance of a new disease in farmed rainbow trout in Norway in 2013 [11] led to the detection of a virus with $80 \%$ gene sequence homology to PRV-1, and further characterization of the virus concluded that it was a subtype of PRV, named PRV-3. Infectious trials were conducted to assess the risk associated with introduction of the new virus in salmonid aquaculture [12], which 

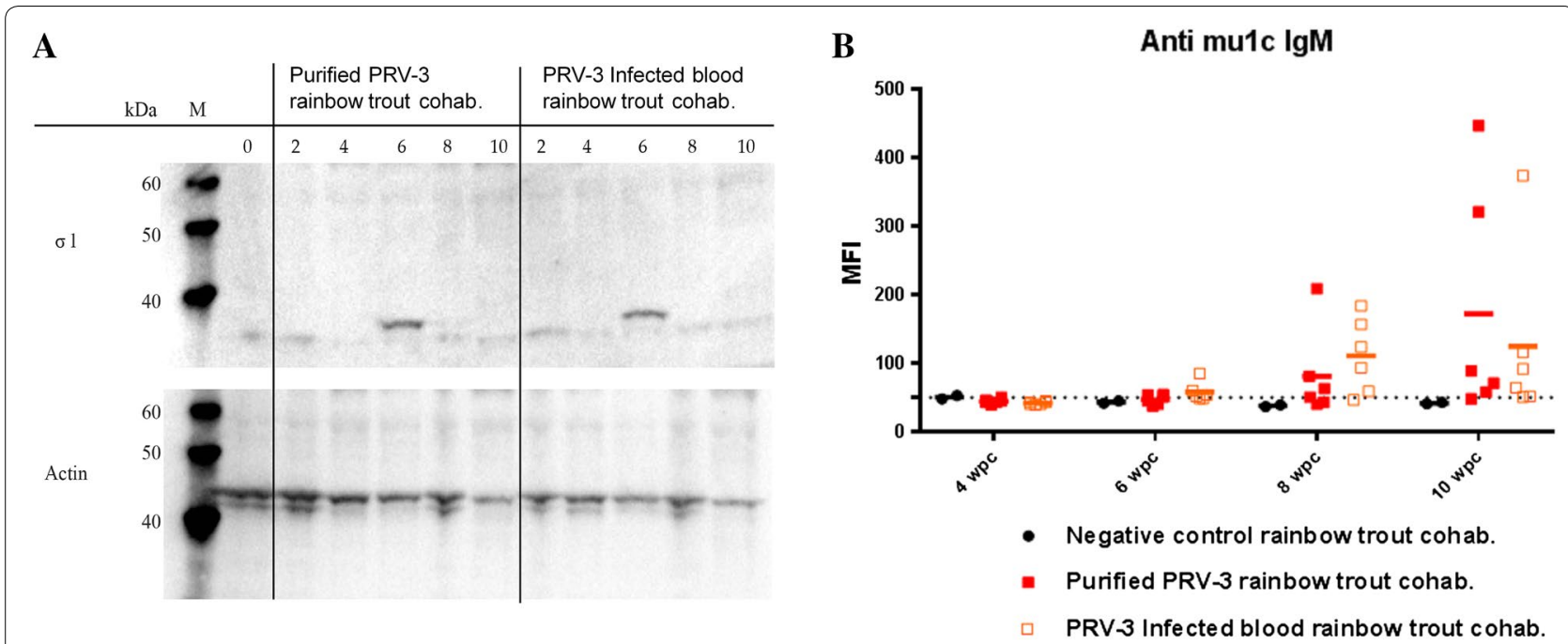

Figure 4 PRV-3 proteins in blood cells and anti-PRV-3 antibodies in plasma. A Western blot analysis of blood cell pellets from cohabitants to purified PRV-3 injected fish. B Multiplex analysis of PRV-3 $\mu 1 \mathrm{c}$ specific antibodies in cohabitant fish measured in Mean fluorescence intensity (MFI). Six fish were tested per sampling and group.

indicated that the virus infects and replicates more effectively in rainbow trout than in Atlantic salmon. PRV-3 has been detected in several salmonid farming countries including Scotland, Germany, Italy, Denmark and Chile $[13,16,17]$, but not always associated with clinical disease. Therefore, further investigations of the host-pathogen interaction could provide knowledge of benefit for fish health management.

The resistance of PRV to in vitro cultivation in available cell lines led to an approach where the virus was purified from experimentally infected fish as demonstrated by Wessel et al. [3] for PRV-1 and by Takano et al. [8] for PRV-2. Here, we adopted this approach by propagating PRV-3 in experimentally infected rainbow trout and purifying the virus by density $\mathrm{CsCl}$ gradient ultracentrifugation, as described by Wessel et al. [3]. The purity of viral particles was confirmed by analyzing the fraction by Next Generation Sequencing-NGS [13]. In EM, PRV-3 particles show similar features to the one displayed by purified PRV-1, i.e. the spherical particles with icosahedral symmetry with a diameter of approximately $75 \mathrm{~nm}$, and two concentric electron dense layers representing the double capsid (Figure 1A).

Notably, fish exposed to PRV-3 by cohabitation had higher viral loads than the injected groups, suggesting that the cohabitation challenge model is suitable for investigation of PRV infection.

Fish challenged with purified PRV-3 by cohabitation were infected, as seen by the presence of $\sigma 1$ protein at 6 wpc as demonstrated by western blot of pelleted blood cells and by the increase of qPCR positive fish after cohabitation. The timing of this is similar to PRV-1 infection in Atlantic salmon [32].

PRV-1 establishes a persistent infection in Atlantic salmon, and viral RNA can be detected for at least 57 wpc [33]. On the contrary, we observed that experimental PRV-3 infection in rainbow trout was characterized by significant clearance over time, in line with a previous study [12]. More specifically, the number of positive fish and virus levels per sampling point decreased after peak viremia. This trend of the infection kinetics was observed in both infected groups in our trial. In the positive control tank the injected fish reached peak virus levels already $2 \mathrm{wpc}$, whereas in the group injected with purified PRV-3 particles the peak was 4 wpc. Most likely, this difference can be explained by lower viral load in the initial inoculum, i.e. Ct 26.3 in PRV-3 infected blood, and Ct 32.67 in the purified PRV-3 inoculum.

The finding of PRV-specific antibody response from 8 wpc directed against the outer capsid protein PRV-1 $\mu 1 C$ showed that the infection was recognized by the fish humoral response. Temporally, PRV-specific antibodies were detectable 2 weeks following the peak viral load and presumably the main shedding period which occurred at 6 wpc in cohabitants.

PRV-3 infection in rainbow trout did not cause reduced survival, neither in the positive control group nor in the group challenged with purified PRV-3 particles, consistent with what is previously observed under experimental conditions [12].

PRV-3 challenged fish developed typical heart pathology; a pancarditis, where all parts of the heart were 

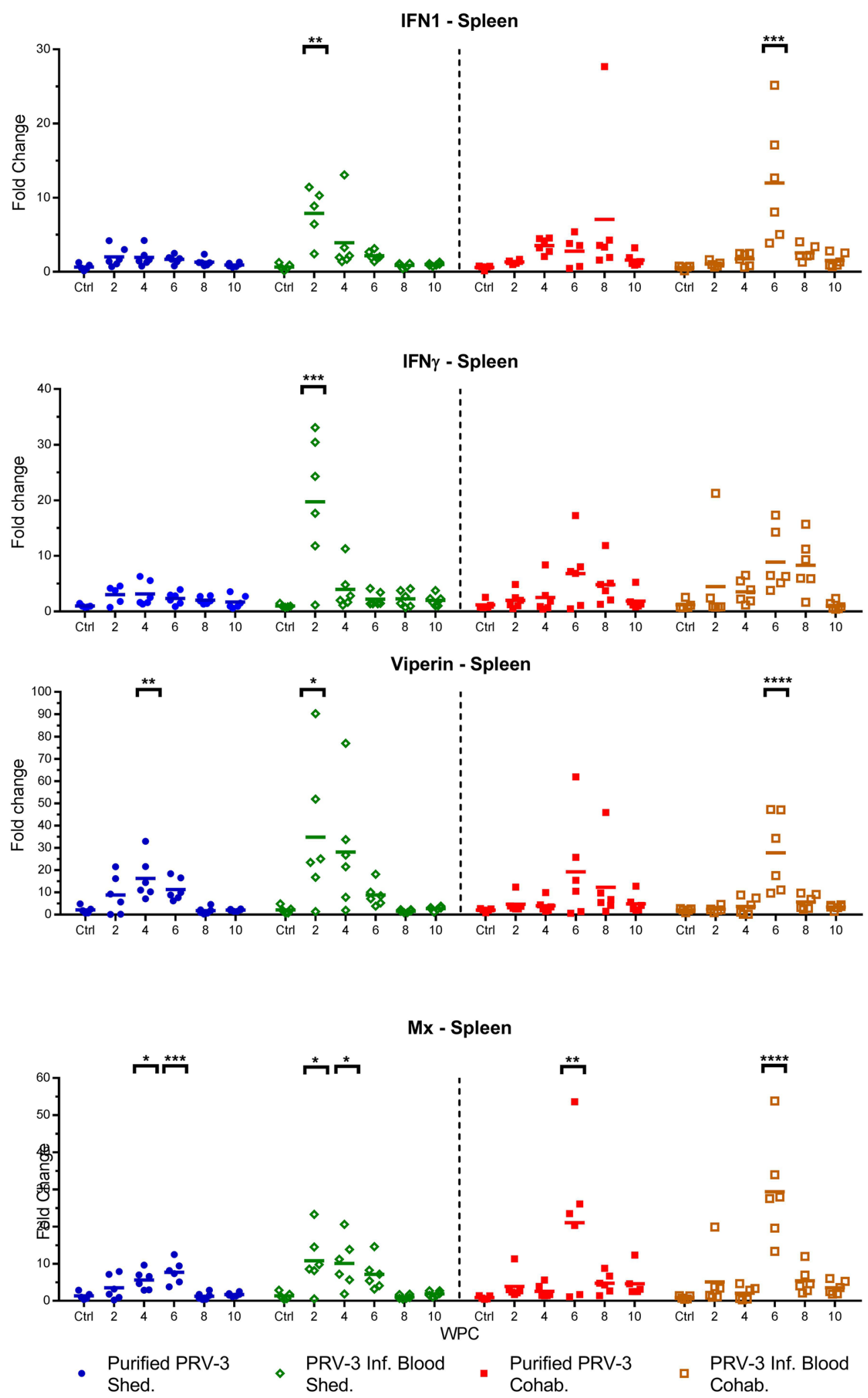

Figure 5 Innate antiviral immune gene expression in spleen of PRV-3 challenged fish. Relative expression of IFN1, IFNy, Mx, and Viperin in controls, pure virus injected fish, blood pellet injected fish and their respective cohabitant groups $(n=6)$. The Ct values were normalized against control fish from 0 wpc. Significant differences compared to control are shown in asterisks ${ }^{*} P<0.05{ }^{* *} P<0.01,{ }^{* * *} P<0.001,{ }^{* * * *} P<0.0001$. 
affected. This was more pronounced in fish challenged with PRV-3 infected blood, nevertheless fish exposed to purified PRV-3 particles had these heart lesions. Although mild, the histopathological findings in the experimental group were consistent with a pathology described in field cases [11], from previous experiments [12] and the same as observed in the positive control group in this study.

An attempt to stain PRV antigen by immunohistochemistry in heart sections from fish with high viral loads with a polyclonal antibody against PRV-1 failed. This could be explained by low sensitivity of the antibodies in IHC, i.e. the amount of viral antigen was too low for detection. Another explanation could be conformational differences between PRV-1 and PRV-3. PRV-3 antigen can be detected in western blots under denaturing conditions, but it highlights the need for development of specific tools for identifying the localization of PRV-3 in tissue.

Our results linked the presence of the virus to the consecutive development of pathology in the heart, but furthermore also to the upregulation of CD8 and CD4 lymphocyte markers in this organ. The PRV-3 load peaked at 6 wpc in cohabitants, 4 weeks before the increased expression of CD8 $+\mathrm{T}$ cell population marker in the heart.

The increased level of the CD8+ $\mathrm{T}$ cell transcripts was associated with the observation of heart pathology, as previously observed in Atlantic salmon [32, 34]. This finding strengthens the link between CD8+ cytotoxic cells and heart inflammation, and indicates that the mechanisms of Norwegian PRV-1 induced HSMI [34] is paralleled by the pathogenesis of the PRV-3 induced heart pathology. The study highlighted some similarities between PRV-1 infection in Atlantic salmon and PRV-3 infection in rainbow trout. The two viral subtypes shares $80 \%$ homology at the genetic level [13], they target the respective host erythrocytes for replication and cause similar inflammatory lesion in the heart of infected fish. Both viral subtypes trigger similar immune responses in the respective hosts. Conversely, PRV-1 establishes a persistent infection in Atlantic salmon while our findings indicate that PRV-3 infection could be of limited duration in rainbow trout. Notably, PRV-3 affected rainbow trout in field outbreaks suffer severe anaemia [11], which is not reported for HSMI in Atlantic salmon. Furthermore typical PRV-3 outbreaks in rainbow trout occurred in fresh water, whereas HSMI is most common after sea transfer.

The innate antiviral gene regulation in the present study followed the PRV-3 kinetics, thus strengthening the association between PRV load and innate antiviral responses in infected salmonids $[3,12,34,35]$. The innate antiviral gene upregulation in the early stage of PRV-3 infection may efficiently hamper the progression of viral infection, and lead to the decreased viral load after 6 wpc. Differences have been observed for HSMI and in innate antiviral response after PRV-1 challenge of Atlantic salmon indicating that viral and/or host genetic factors influence the outcome of a PRV-1 infection [3, 33]. For Mammalian orthoreovirus it has been shown that the ability to induce IFN contributes to the differences in the development of myocarditis [36, 37].

Previous studies [12] have shown how experimental infection in Atlantic salmon with PRV-3 infected blood failed to induce host innate immune response. Moreover, experimental infection in sockeye salmon (Oncorhynchus nerka) with PRV-1 fail to induce IFN related genes [38], whereas PRV-1 infection successfully trigger IFN related immune response modulating the susceptibility of Atlantic salmon to subsequent challenge with Infectious haematopoietic necrosis virus-IHNV or Salmonid alphavirus-SAV [35, 39, 40].

PRV infection of farmed salmonids can broadly be divided into two different clinical manifestations. (1) An acute disease, EIBS, which is a direct consequence of severe anemia at the peak of viremia, as seen in PRV-2 infection of coho salmon. It could be speculated that the jaundice syndrome described in Chinook salmon (related to PRV-1) [41] and jaundice syndrome reported in coho salmon (related to PRV-3) [16, 17] are downstream consequences of the clearance process of infected erythrocytes. Yet the role of PRV-1 and PRV-3 in the development of anaemia remains unknown. PRV-1 infection under experimental conditions failed to induce anaemia in Sockeye salmon [33, 38]. In Atlantic salmon, experimental infection with PRV-1 has only occasionally led to reduction of haematocrit and haemoglobin levels [35]. Notably, in this study, high loads of PRV-3 were generated in rainbow trout without causing a reduction of haematocrit, albeit it is described in disease outbreaks associated with PRV-3 in the field [11]. These findings might suggest that other factors, possibly related to farming conditions, are involved in the development of anaemia in clinical outbreaks. (2) HSMI, which appears a few weeks after the viraemia peak as demonstrated for PRV-1 in Atlantic salmon, is characterized by inflammation seen as influx of CD8 lymphocytes in heart tissue [34, 42]. In field outbreaks associated with PRV-3 reported by Olsen et al. [11], 113 fish were examined for histopathology. Amongst these, 80 fish showed evident clinical signs and 33 apparently looked healthy. A heart pathology resembling HSMI was described in 103 of the 113 fish examined [11]. In the current study, no clinical signs were observed, and an HSMI-like pathology was observed in a limited number of fish. Yet, in line with the timing of observation of heart pathology after PRV-1 infection in 
Atlantic salmon [19], the HSMI related histopathological findings in the heart in the present experiment were observed in the later stage of the trial, i.e. at $6 \mathrm{wpc}$ in the injected group and $10 \mathrm{wpc}$ in the cohabitant group.

In conclusion, the findings of this study support the hypothesis that establishes the causative relationship between PRV-3 infection in rainbow trout and the development of pancarditis as described for HSMI in Atlantic salmon. Furthermore, the identification of the aetiological agent, makes a basis for the development of specific preventive tools and control strategies. The recent emergence of PRV-3 variants in rainbow trout farms associated with severe disease outbreaks [13], warrants further investigation in search of factors that modulate the severity of the disease.

\section{Additional file}

Additional file 1. Proportion of fish showing histopathological findings not consistent with PRV-induced inflammation. The findings consisted of epicarditis and a focal inflammatory reaction involving the interface layer between stratum compactum and stratum spongiosum of the ventricle. These were randomly distributed throughout the experiment and observed in all groups.

\section{Competing interests}

The authors declare that they have no competing interests.

\section{Authors' contributions}

NJO, NV and ER launched the project idea. NJO, KD, NV and ER participated in the overall design and coordination of the study, interpretation of data and drafting the manuscript. KD and NV conducted the trial, performed sampling and tested samples for viral kinetics. KD and MKD performed gene expression analysis. ABO and TMI performed histopathological examination of samples collected. LHT and MKD performed immunoassay for PRV antibody detection. $\varnothing \mathrm{W}, \mathrm{TMI}, \mathrm{MKD}, \mathrm{AC}$ and $\mathrm{ABO}$ participated in the coordination of the study, revised the manuscript and provided significant contribution to figures and text. All authors read and approved the final manuscript.

\section{Acknowledgements}

This study was co-funded by the European Reference Laboratory for Fish diseases at DTU AQUA National Institute of Aquatic Resources and H2020 INFRAIA-1-2014/2015 Aquaexcel grant agreement No 652831. Immune gene analysis and immunoassays were financed by the Norwegian Research Council (NRC) (Bioforsk Grant \# 237315/E40) (ViVaFish). K.D. acknowledges the financial assistance provided by the Indian Council of Agricultural Research (ICAR) through the [National Bureau of Agriculturally Important Microorganisms (ICAR International Fellowship)] for his PhD. Histopathology was financed by the Norwegian Veterinary Institute (NVI). A special thanks to the Unit for fish and shellfish diseases at DTU-AQUA and the teams at NVI in Oslo and Bergen for technical support during the study.

\section{Author details}

${ }^{1}$ National Institute of Aquatic Resources, Technical University of Denmark, Kongens Lyngby, Denmark. ${ }^{2}$ Department of Food Safety and Infection Biology, Norwegian University of Life Sciences, Oslo, Norway. ${ }^{3}$ Norwegian Veterinary Institute, Bergen, Norway. ${ }^{4}$ Norwegian Veterinary Institute, Oslo, Norway.

\section{Ethics approval and consent to participate}

The experiments were carried out in the facilities at DTU-VET (Frederiksberg, Denmark) in accordance with the recommendations in the current animal welfare regulations under the license 2013-15-2934-00976. The protocols were approved by the Danish Animal Research Authority.

\section{Publisher's Note}

Springer Nature remains neutral with regard to jurisdictional claims in published maps and institutional affiliations.

Received: 31 August 2018 Accepted: 3 January 2019

Published online: 18 February 2019

\section{References}

1. Markussen T, Dahle MK, Tengs T, Løvoll M, Finstad ØW, Wiik-Nielsen CR, Grove S, Lauksund S, Robertsen B, Rimstad E (2013) Sequence analysis of the genome of piscine orthoreovirus (PRV) associated with heart and skeletal muscle inflammation (HSMI) in Atlantic salmon (Salmo salar). PLoS One 8:e70075

2. Wessel $\varnothing$, Olsen CM, Rimstad E, Dahle MK (2015) Piscine orthoreovirus (PRV) replicates in Atlantic salmon (Salmo salar L.) erythrocytes ex vivo. Vet Res 46:26

3. Wessel $\varnothing$, Braaen $S$, Alarcon M, Haatveit $H$, Roos N, Markussen T, Tengs T, Dahle MK, Rimstad E (2017) Infection with purified Piscine orthoreovirus demonstrates a causal relationship with heart and skeletal muscle inflammation in Atlantic salmon. PLoS One 12:e0183781

4. Palacios G, Lovøll M, Tengs T, Hornig M, Hutchison S, Hui J, Kongtorp RT, Savji N, Bussetti AV, Solovyov A, Kristoffersen AB, Celone C, Street C, Trifonov V, Hirschberg DL, Rabadan R, Egholm M, Rimstad E, Lipkin WI (2010) Heart and skeletal muscle inflammation of farmed salmon is associated with infection with a novel reovirus. PLoS One 5:e11487

5. Kongtorp RT, Kjerstad A, Taksdal T, Guttvik A, Falk K (2004) Heart and skeletal muscle inflammation in Atlantic salmon, Salmo salar L.: a new infectious disease. J Fish Dis 27:351-358

6. Di Cicco E, Ferguson HW, Schulze AD, Kaukinen KH, Li S, Vanderstichel R, Wessel Ø, Rimstad E, Gardner IA, Hammell KL, Miller KM (2017) Heart and skeletal muscle inflammation (HSMI) disease diagnosed on a British Columbia salmon farm through a longitudinal farm study. PLoS One 12:e0171471

7. Kongtorp RT, Taksdal T, Lyngoy A (2004) Pathology of heart and skeletal muscle inflammation (HSMI) in farmed Atlantic salmon Salmo salar. Dis Aquat Organ 59:217-224

8. Takano T, Nawata A, Sakai T, Matsuyama T, Ito T, Kurita J, Terashima S, Yasuike M, Nakamura Y, Fujiwara A, Kumagai A, Nakayasu C (2016) Full-genome sequencing and confirmation of the causative agent of erythrocytic inclusion body syndrome in coho salmon identifies a new type of piscine orthoreovirus. PLoS One 11:e0165424

9. Landolt ML, MacMillan JR, Patterson M (1977) Detection of an intra-erythrocytic virus in rainbow trout (Salmo gairdneri). Fish Health News 6:4-6

10. Leek SL (1987) Viral erythrocytic inclusion body syndrome (EIBS) occurring in juvenile spring chinook salmon (Oncorhynchus tshawytscha) reared in freshwater. Can J Fish Aquat Sci Aquat Sci 44:685-688

11. Olsen AB, Hjortaas M, Tengs T, Hellberg H, Johansen R (2015) First description of a new disease in rainbow trout (Oncorhynchus mykiss Walbaum) similar to heart and skeletal muscle inflammation (HSMI) and detection of a gene sequence related to piscine orthoreovirus (PRV). PLoS One 10:e0131638

12. Hauge $H$, Vendramin $N$, Taksdal T, Olsen ABAB, Wessel $\varnothing$, Mikkelsen SS, Alencar ALF, Olesen NJ, Dahle MK (2017) Infection experiments with novel Piscine orthoreovirus from rainbow trout (Oncorhynchus mykiss) in salmonids. PLoS One 12:e0180293

13. Dhamotharan $K$, Vendramin N, Markussen T, Wessel $\varnothing$, Cuenca A, Nyman IBIB, Olsen ABAB, Tengs T, Dahle MK, Rimstad E (2018) Molecular and antigenic characterization of piscine orthoreovirus (PRV) from rainbow trout (Oncorhynchus mykiss). Viruses 10:E170

14. Gjevre AG, Modahl I, Spilsberg B, Lyngstadrt TM (2016) The surveillance programme for virus associated with disease in rainbow trout (PRVom) in 2016. The Norwegian Veterinary Institute 2016. https://www.vetinst.no/ overvaking/Piscine-orthoreovirus-Oncorhynchus-mykiss-PRVom-fisk/ / attachment/download/d6ff8741-307e-4c30-8456-50b85002b678:1 c508 
8843c6f2c7dd4bc6e8c0c1d8fdcaad7c921/2017_OK_PRVom_2016.pdf. Accessed June 2018

15. Kuehn R, Bc Stoeckle, Young M, Popp L, Taeubert E, Pfaffl MW, Geist J (2018) Identification of a piscine reovirus-related pathogen in proliferative darkening syndrome (PDS) infected brown trout (Salmo trutta fario) using a next-generation technology detection pipeline. PLoS One 13:e0206164

16. Bohle H, Bustos P, Leiva L, Grothusen H, Navas E, Sandoval A, Bustamante F, Montecinos K, Alvaro Gaete MM (2018) First complete genome sequence of piscine orthoreovirus variant 3 infecting coho salmon (Oncorhynchus kisutch) farmed in southern Chile. Genome Announc 6:e00484-18

17. Godoy MG, Kibenge MJT, Wang Y, Suarez R, Leiva C, Vallejos F, Kibenge FSB (2016) First description of clinical presentation of piscine orthoreovirus (PRV) infections in salmonid aquaculture in Chile and identification of a second genotype (Genotype II) of PRV. Virol J 13:98

18. Bruner R, Vinograd J (1965) The evaluation of standard sedimentation coefficients of sodium RNA and sodium DNA from sedimentation velocity data in concentrated $\mathrm{NaCl}$ and $\mathrm{CsCl}$ solutions. Biochim Biophys Acta 108:18-29

19. Finstad ØW, Falk K, Løvoll M, Evensen $\varnothing$, Rimstad E (2012) Immunohistochemical detection of piscine reovirus (PRV) in hearts of Atlantic salmon coincide with the course of heart and skeletal muscle inflammation (HSMI). Vet Res 43:27

20. Teige LH, Lund M, Haatveit HM, Røsæg MV, Wessel Ø, Dahle MK, Storset AK (2017) A bead based multiplex immunoassay detects Piscine orthoreovirus specific antibodies in Atlantic salmon (Salmo salar). Fish Shellfish Immunol 63:491-499

21. Kongtorp RT, Halse M, Taksdal T, Falk K (2006) Longitudinal study of a natural outbreak of heart and skeletal muscle inflammation in Atlantic salmon, Salmo salar L. J Fish Dis 29:233-244

22. Dunnett CW (1955) A multiple comparison procedure for comparing several treatments with a control. J Am Stat Assoc 50:1096-1121

23. Spearman C (1904) The proof and measurement of association between two things. Am J Psychol 15:72-101

24. Cohen J (1890) The evolution of Koch's postulates. In: Cohen J, William PG, Steven OD (eds) Infectious Diseases, $4^{\text {th }}$ edn. Elsevier

25. Rivers TM (1937) Viruses and Koch's postulates. J Bacteriol 33:1-12

26. Fredricks DN, Relman DA (1996) Sequence-based identification of microbial pathogens : a reconsideration of Koch's. Clin Microbiol Rev 9:18-33

27. Tengs T, Rimstad E (2017) Emerging pathogens in the fish farming industry and sequencing-based pathogen discovery. Dev Comp Immunol 75:109-119

28. Haugland O, Mikalsen AB, Nilsen P, Lindmo K, Thu BJ, Eliassen TM, Roos N, Rode M, Evensen O (2011) Cardiomyopathy syndrome of Atlantic salmon (Salmo salar L.) is caused by a double-stranded RNA virus of the Totiviridae family. J Virol 85:5275-5286

29. Garseth H, Fritsvold C, Svendsen JC, Bang Jensen B, Mikalsen AB (2018) Cardiomyopathy syndrome in Atlantic salmon Salmo salar L.: a review of the current state of knowledge. J Fish Dis 41:11-26

30. Gjessing MC, Yutin N, Tengs T, Senkevich T, Koonin E, Rønning HP, Alarcon M, Ylving S, Lie K-I, Saure B, Tran L, Moss B, Dale OB (2015) Salmon gill poxvirus, the deepest representative of the Chordopoxvirinae. J Virol 89.9348-9367

31. Gjessing MC, Thoen E, Tengs T, Skotheim SA, Dale OB (2017) Salmon gill poxvirus, a recently characterized infectious agent of multifactorial gill disease in freshwater- and seawater-reared Atlantic salmon. J Fish Dis 40:1253-1265
32. Haatveit HM, Wessel $\varnothing$, Markussen T, Lund M, Thiede B, Nyman IB, Braaen S, Dahle MK, Rimstad E (2017) Viral protein kinetics of piscine orthoreovirus infection in atlantic salmon blood cells. Viruses 9:E49

33. Garver KA, Johnson SC, Polinski MP, Bradshaw JC, Marty GD, Snyman HN, Morrison DB, Richard J (2016) Piscine orthoreovirus from western North America is transmissible to Atlantic salmon and sockeye salmon but fails to cause heart and skeletal muscle inflammation. PLoS One 11:e0146229

34. Mikalsen AB, Haugland O, Rode M, Solbakk IT, Evensen O (2012) Atlantic salmon reovirus infection causes a CD8 T cell myocarditis in atlantic salmon (Salmo salar L.). PLoS One 7:e37269

35. Vendramin N, Alencar ALF, Iburg TM, Dahle MK, Wessel O, Olsen AB, Rimstad E, Olesen NJ (2018) Piscine orthoreovirus infection in Atlantic salmon (Salmo salar) protects against subsequent challenge with infectious hematopoietic necrosis virus (ihnv). Vet Res 49:30

36. Sherry B, Torres J, Blum MA (1998) Reovirus induction of and sensitivity to beta interferon in cardiac myocyte cultures correlate with induction of myocarditis and are determined by viral core proteins. J Virol 72:1314-1323

37. Irvin SC, Zurney J, Ooms LS, Chappell JD, Dermody TS, Sherry B (2012) A single-amino-acid polymorphism in reovirus protein $\mu 2$ determines repression of interferon signaling and modulates myocarditis. J Virol 86:2302-2311

38. Polinski MP, Bradshaw JC, Inkpen SM, Richard J, Fritsvold C, Poppe TT, Rise ML, Garver KA, Johnson SC (2016) De novo assembly of Sockeye salmon kidney transcriptomes reveal a limited early response to piscine reovirus with or without infectious hematopoietic necrosis virus superinfection. BMC Genomics 17:848

39. Røsæg MV, Lund M, Nyman IB, Markussen T, Aspehaug V, Sindre H, Dahle MK, Rimstad E (2017) Immunological interactions between Piscine orthoreovirus and Salmonid alphavirus infections in Atlantic salmon. Fish Shellfish Immunol 64:308-319

40. Lund M, Røsæg MV, Krasnov A, Timmerhaus G, Nyman IB, Aspehaug V, Rimstad E, Dahle MK (2016) Experimental Piscine orthoreovirus infection mediates protection against pancreas disease in Atlantic salmon (Salmo salar). Vet Res 47:107

41. Di Cicco E, Ferguson HW, Kaukinen KH, Schulze AD, Li S, Tabata A, Günther OP, Mordecai G, Suttle CA, Miller KM (2018) The same strain of Piscine orthoreovirus (PRV-1) is involved with the development of different, but related, diseases in Atlantic and Pacific Salmon in British Columbia. Facets 3:599-641

42. Yousaf MN, Koppang EO, Skjødt K, Hordvik I, Zou J, Secombes C, Powell MD (2013) Comparative cardiac pathological changes of Atlantic salmon (Salmo salar L.) affected with heart and skeletal muscle inflammation (HSMI), cardiomyopathy syndrome (CMS) and pancreas disease (PD). Vet Immunol Immunopathol 151:49-62

43. Ballesteros NA, Rodriguez Saint-Jean S, Perez-Prieto SI (2015) Immune responses to oral pcDNA-VP2 vaccine in relation to infectious pancreatic necrosis virus carrier state in rainbow trout Oncorhynchus mykiss. Vet Immunol Immunopathol 165:127-137

44. Wangkahart E, Scott C, Secombes CJ, Wang T (2016) Re-examination of the rainbow trout (Oncorhynchus mykiss) immune response to flagellin: Yersinia ruckeri flagellin is a potent activator of acute phase proteins, antimicrobial peptides and pro-inflammatory cytokines in vitro. Dev Comp Immunol 57:75-87 